\title{
A 14-year-old with lateral knee pain and locking
}

\section{Sachin Dheer • Chad Silverberg • Adam C. Zoga •}

William B. Morrison

Received: 12 July 2011 /Accepted: 12 September 2011 / Published online: 10 November 2011

(C) ISS 2011

\section{Question}

A 14-year-old boy presented with lateral knee pain, swelling, and an inability to fully extend his knee following recreational tennis (Fig. 1).

The diagnosis can be found at doi:10.1007/s00256-011-1286-0.

S. Dheer $(\bowtie)$

Department of Radiology, Kennedy Health System,

2201 Chapel Avenue,

Cherry Hill, NJ 08002, USA

e-mail: sachdheer@yahoo.com

C. Silverberg

Progressive Radiology,

7799 Leesburg Pike,

Falls Church, VA 22043, USA

A. C. Zoga $\cdot$ W. B. Morrison

Department of Radiology, Thomas Jefferson University Hospital,

Philadelphia, PA 19107, USA 
Fig. 1 a Axial 2D T2*-weighted imaging demonstrated an ovoid, low-signal structure measuring approximately $7 \mathrm{~mm}$ (arrow) superficial to the lateral femoral condyle at the level of the popliteal hiatus, deep to the tensor fascia lata, anterior to the fibular collateral ligament and associated with the popliteus tendon (curved arrow). b Coronal T1-weighted image demonstrated a corticated osseous structure with internal cancellous bone signal (arrow). c Sagittal T2-weighted,

fat-saturated image confirmed the ovoid shape of the structure, and demonstrated intense internal bone marrow edema signal (arrow) with surrounding soft tissue edema. The fibular collateral ligament was identified immediately posteriorly (curved arrow). d Coronal STIR image demonstrated bone marrow edema within the lateral margin of the lateral femoral condyle (arrow)
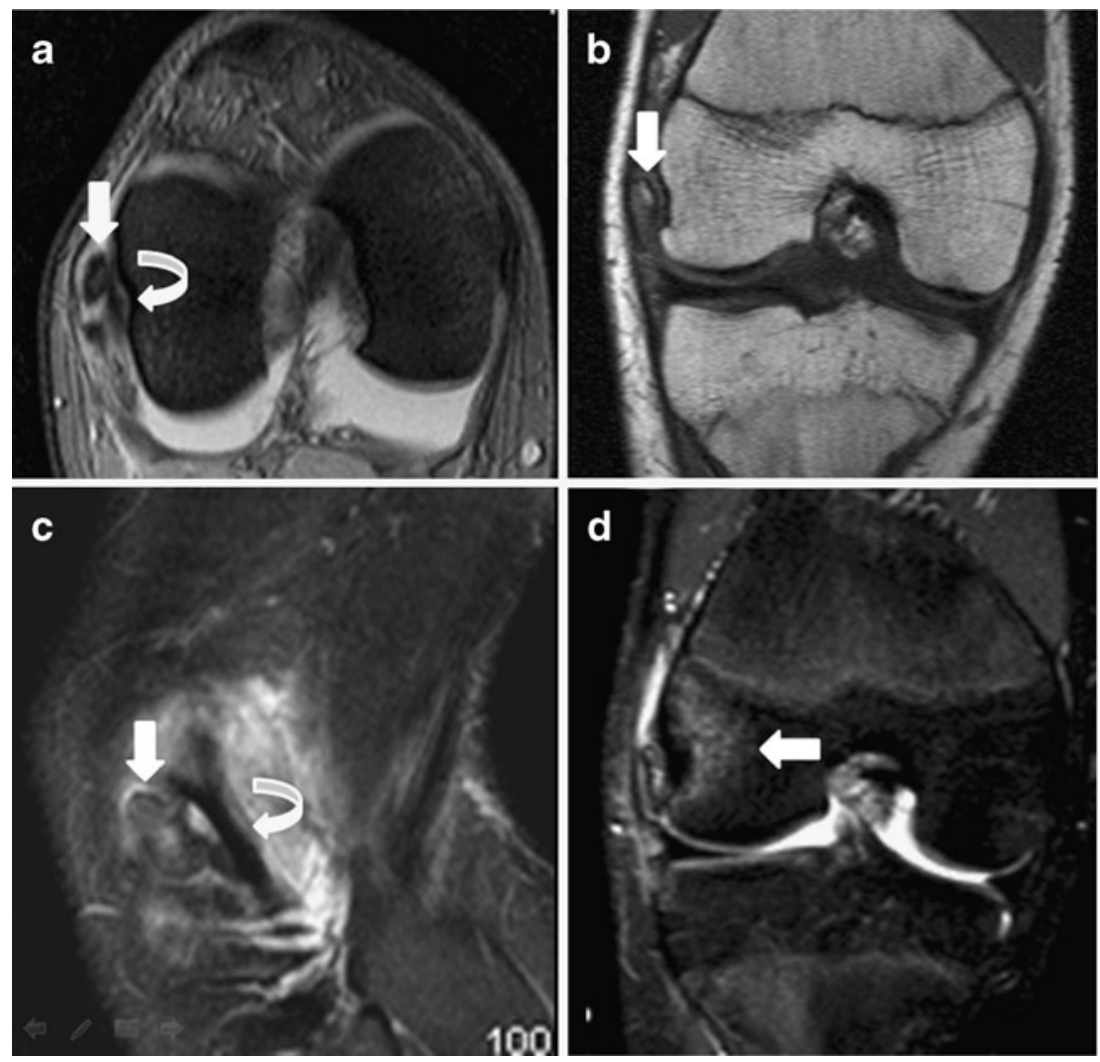